\title{
ARQUITECTURA Y MULTICULTURALISMO HACIA UN ENTORNO SIGNIFICATIVO MÁS ALLÁ DE LA GLOBALIZACIÓN Y LA FRAGMENTACIÓN CULTURAL*
}

\author{
Alberto Pérez-Gómez \\ Doctor en Arquitectura e Historia Profesor McGill Canadá
}

https://dx.doi.org/10.12795/astragalo.2018.i24.12

\begin{abstract}
Este ensayo arguye que a pesar de la opinión tecnocrática que generalmente niega su importancia, la arquitectura -en un sentido histórico que intentaré definir aquí brevemente- es crucial para el bienestar humano. Un entorno constituido únicamente por productos de consumo a la moda, que hable simplemente de procesos tecnológicos eficientes o de ideologías, tiene consecuencias nefastas pues contribuye a inculcar un nihilismo que resulta en psicopatologías colectivas: la ansiedad de no pertenecer a nada, de sentir que no podemos sentir y la percepción de que el entorno es hostil y todos nuestros actos son fútiles.
\end{abstract}

Es mi intención establecer algunos criterios para concebir una arquitectura capaz de construir un mundo emotivo y con significados apropiados para responder a los valores cultu- rales reales que existen en el mundo cotidiano, donde conviven culturas diversas, un mundo intercultural que parece homogeneizado por las telecomunicaciones, pero donde las diferencias llegan a acentuarse como resultado, paradójico para algunos, de la supuesta transparencia de los medios.

Las conclusiones más interesantes en la neurobiología y las ciencias cognitivas contemporáneas, apoyándose durante los últimos diez años en los descubrimientos de la fenomenología de Edmund Husserl y Maurice Merleau-Ponty, han demostrado la importancia del entorno para nuestra conciencia. ${ }^{1}$ Nuestra mente no termina en el cráneo: nuestra cons-

1 Evan Thompson, Mind in Life (Cambridge MA: Harvard University Press, 2010); Alva Noë, Action in Perception (Cambridge, MA: MIT Press, 2004).

\footnotetext{
*Escrito como Ponencia Magistral para el 3er Foro Internacional de Multiculturalidad en el Instituto Politécnico Nacional, Ciudad de México, 2013.
} 
ciencia es encarnada, distribuida en todo nuestro organismo y éste está, invariablemente ubicado en un lugar. En otras palabras, el sentido de personalidad con que nos identificamos cada mañana al despertar, la primera persona que somos como complejo de conceptos y emociones -el ser que primeramente siente y luego piensa-no sobreviviría si nuestro cerebro fuese separado de nuestro cuerpo con sus sensaciones sinestésicas y su kinestesia o motilidad primordial, conectado con su ambiente a través de diversas modalidades perceptivas: la visión de origen cartesiano que nos ofrecen las películas de ciencia ficción donde supuestamente la personalidad de algún genio maligno sobrevive en su cerebro mantenido artificialmente en una botella de formol es una total falacia.

Es importantísimo por lo tanto, ponderar la influencia de los entornos urbanos y arquitectónicos, de su capacidad para dar lugar a atmosferas apropiadas, armónicas o disonantes para las acciones humanas, ya que son los ambientes urbanos, en sus diversas encarnaciones, en donde vive más del cincuenta por ciento de la humanidad, formando un sistema donde las distinciones tradicionales entre objetividad y subjetividad, cultura y naturaleza, pierden su sentido. La conciencia explicada a través de la dualidad cartesiana que arguye una separación entre cuerpo (como entidad física externa) y mente (como entidad espiritual interna) ha sido ampliamente cuestionada en la filosofía del siglo XX y más recientemente, en múltiples trabajos científicos.

La mente, como sensibilidad primordial, tiene su origen en la biología de la bacteria unicelular, el primer sistema metabólico autonómico, y en cuanto conciencia humana es inseparable del entorno cultural que la modifica e incluso contribuye a la determinación de su destino hereditario (que no es ya atribuible únicamente a la bioquímica genética). El entorno no sólo nos debe confirmar el significado que nuestro ser biológico percibe como propósito en forma inmanente, sino que, al funcionar correctamente, la relación con los lenguajes que caracterizan nuestras ricas culturas humanas, nos debe revelar a través de la emoción y la razón, la riqueza de nuestras vidas, nuestras respectivas identidades y diferencias que hacen posible la comunicación y nuestro lugar como individuos en la sociedad. Esta simple reflexión pone inmediatamente en evidencia la importancia de las profesiones del diseño a toda escala y revela su crucial dimensión ética, imposible de separar, como se piensa habitualmente, de las cuestiones estéticas.

Entendida así, la arquitectura es crucial. Un entorno banal constituido únicamente por productos de consumo a la moda, que hable simplemente de procesos tecnológicos eficientes o de ideologías, tiene consecuencias nefastas pues contribuye a inculcar un nihilismo que resulta en peligrosas psicopatologías colectivas: la ansiedad de no pertenecer a nada, de percibir incluso que no podemos sentir -que nos es difícil amar o lamentar la ausencia o la perdida de algún ser querido-; de que el entorno es hostil y nuestros actos son insubstanciales, incluso triviales para nosotros mismos y nuestras sociedades.

Sin pretender ser prescriptivo, es posible establecer algunos criterios para concebir una arquitectura capaz de construir un mundo emotivo y dado con significados apropiados para responder a valores culturales reales que tienen aún raíces en el mundo cotidiano donde conviven culturas diversas, un mundo intercul- 
tural que parece homogeneizado por las telecomunicaciones, pero donde, paradójicamente, las diferencias llegan a acentuarse más como resultado de la supuesta transparencia de los medios masivos de comunicación. ${ }^{2}$

La producción arquitectónica reciente, sobre todo aquella supuestamente de vanguardia, generalmente celebra el uso de computadoras para generar formas inverosímiles y espacios inusitados. Esta aplicación de la tecnología informática en el diseño ha dejado atrás su primera justificación utilitaria como herramienta para mejorar la eficiencia de la producción arquitectónica, y ahora se ve legitimada por la capacidad de las computadoras para generar formas novedosas a partir de algoritmos.

El resultado, en cierto sentido admirable, son edificios con formas nunca vistas y totalmente distintas de nuestras edificaciones ortogonales. Tales proyectos a menudo se valoran como mercancías por su capacidad de atraer los dólares del turismo y consecuentemente brotan como hongos en los cuatro rincones del planeta. Esta inusitada capacidad de experimentalismo formal, siempre en busca de lo novedoso como objeto de consumo, capaz de producir formas fotogénicas generalmente asociadas con algún supuesto autor genial que adquiere el estatus de estrella cinematográfica, ha contribuido a dejar de lado toda consideración ética en el proyecto arquitectónico.

La atención hacia precedentes históricos y a las condiciones topográficas y cualitativas del lugar donde echaré raíces el futuro edificio, cruciales para lograr a través del proyecto un entorno significativo, particularmente en lo que concierne a la dimensión espacial de la

2 Gianni Vattimo, The Transparent Society (Baltimore MA: John Hopkins University Press, 1992). conciencia encarnada cristalizada en los hábitos culturales y las narrativas locales, no juega ningún papel en este tipo de prácticas que hacen gala de su manipulación de los medios de comunicación, y precisamente por esa razón se dan frecuentemente como modelos a seguir para las nuevas generaciones de arquitectos.

Algunas de las justificaciones filosóficas más sofisticadas que se arguyen para este tipo de práctica invocan su origen en la objetividad de las matemáticas y el instrumentalismo tecnológico. Es absolutamente paradójico, incluso contradictorio, que la justificación de estos procesos de diseño se apoye en el supuesto deseo de evitar la subjetividad del arquitecto: las asociaciones de la arquitectura con el poder, la auto-indulgencia en razón del arte y el control político.

El resultado sería en principio equivalente a un idioma universal, a un esperanto arquitectónico capaz de hablar elocuentemente a todo ser humano y de ofrecernos lugares vívidos para nuestro habitar, sin importar nuestro diverso origen cultural. En nuestro mundo post-colonial esta posición se presenta como una posibilidad ética que sería apreciada por cualquiera. Sin embargo, como trataré de hacer evidente a lo largo de este ensayo y en vista de otras alternativas, es importante reconocer que se trata aquí del mismo ideal fallido que subraya todo el modernismo arquitectónico y sus presuposiciones teóricas desde sus inicios en el siglo XIX. La supuesta objetividad de los procesos, ya sea el funcionalismo o el parametricismo, excluyendo a la imaginación hermenéutica: el arquitecto orientado a través del lenguaje histórico y narrativo, no es sino una fórmula para la exclusión de una verdadera posición ética.

Hoy en día las diversidades culturales y regionales se perciben más claramente que du- 
rante la primera mitad del siglo XX. El resultado en cierto modo inusitado de la proliferación de los medios globales de telecomunicación, es que en vez de promover una simple homogeneización, han contribuido a revelar la presencia de múltiples y diversas culturas cuyos valores se conservan y que resultan más genuinos incluso que las ideologías de las estructuras políticas nacionales que las incluyen.

Hoy, por ejemplo, comprendemos con claridad y valorizamos la complejidad de las múltiples culturas mesoamericanas en el origen de México, una situación muy diferente a la que impero durante la mayor parte del siglo XX, después de la Revolución. La imposición del castellano en programas de educación universal es un caso bien documentado. En la escuela se impartía una historia política parcial y simplista, si no distorsionada, arguyendo, por ejemplo, que el origen de México era un supuesto imperio Azteca: paradójicamente una fabricación de los españoles que impusieron su óptica a lo que encontraron en el Nuevo Mundo.

Además de la importante valorización de las diversidades culturales, hoy día las instituciones propias de la modernidad -como el Estado-Nación que fue resultado del pensamiento de la ilustración y de la Revolución Francesaestán en crisis. Giorgio Agamben explica cómo, en razón de la valoración de los derechos humanos universales promulgados a principios del siglo XIX, paradójicamente estas naciones nuestras, incluso las más democráticas, funcionan con técnicas represivas no distintas fundamentalmente de un campo de concentración. ${ }^{3}$

Es con esta conciencia que debemos confrontar las preguntas más esenciales en cuanto

3 Giorgio Agamben, Homo Sacer: Sovereign Power and Bare Life (Stanford CA: Stanford University Press, 1998). que constituye una praxis arquitectónica apropiada para nuestras complejas constelaciones culturales. Estas cuestiones no pueden ser negociadas por una arquitectura resultante de la mera innovación formal generada por algún sistema paramétrico. En otras palabras, no podemos ni debemos dar por hecho que la multiculturalidad resulte necesariamente en una homogeneización y que ésta sea mejor servida por la instrumentalización tecnológica.

Es incuestionable que el mundo globalizado del Internet sugiere nuevas formas y programas para el habitar. Sin embargo, estas formas y programas nunca aparecen emancipadas de algún contexto político donde ingiere la conciencia encarnada, siempre con raíces históricas locales. Aun cuando el uso de parámetros digitales puede concebirse como una posibilidad para superar los viejos debates estilísticos, las ciudades sin jerarquía, determinadas simplemente por la circulación, semejantes a algún colmenar con proporciones humanas, no ofrecen más posibilidades de mejorar nuestra condición humana que las tramas ortogonales del modernismo heroico de 1920.

Cada día el Internet nos ofrece imágenes de edificaciones novedosas que aparentemente manifiestan una arquitectura en efervescencia y que, sin embargo, más allá de la novedad y su valor mercantil, generalmente ignoran sus respectivos contextos físicos y culturales y la primordial dimensión de la experiencia encarnada. Debemos siempre recordar que los edificios, en cuanto experiencia vivida, no son imágenes fotográficas.

Los procesos instrumentales de diseño en la arquitectura, desde los mecanismos de composición funcional heredados del siglo XIX al software del tipo contratado por la nueva 
vanguardia, hoy se emplean sin ningún sentido crítico por todo el planeta, participando a menudo inconscientemente en un mismo sistema de valores. Debemos recordar aquí que la tecnología moderna occidental (hoy universal) no es una operación libre de valores. Su exitoso control del medio ambiente depende de una reducción de la naturaleza -aquella parte fundamental de nuestro entorno que los seres humanos no hemos creado- a meros recursos materiales, supuestamente dados al hombre para su explotación.

Sus operaciones, que asociamos normalmente con las triunfantes revoluciones industriales de los últimos dos siglos, se fundan en la creencia de que las matemáticas son el verdadero lenguaje universal, la gramática de la ciencia aplicada. En nuestra disciplina esto se hace evidente en los productos de una industria de la construcción internacional impulsada por valores tecnológicos, por software como Revit y por los imperativos de la economía.

A pesar de estas suposiciones dominantes, es importante observar que existe una distancia insalvable entre las matemáticas (como supuesto idioma universal) y los idiomas humanos que nuestra especie habla en forma cotidiana y que constituyen el punto de partida de todo sistema simbólico. ${ }^{4}$ Esta reflexión es de gran importancia para entender las posibles características de una arquitectura que responda a las culturas y sea capaz asimismo de comunicación más allá de lo local.

La increíble diversidad de idiomas para una humanidad única, para una misma especie

4 Sobre el lenguaje ver George Steiner, After Babel (Chicago IL: University of Chicago Press, 1989) y Maurice MerleauPonty, The Prose of the World (Evanston IL: Northwestern University Press, 1991), p. $5 \mathrm{f}$. biológica, es uno de los enigmas fundamentales de la cultura humana. En esto el animal humano es totalmente distinto de otras especies animales que poseen diversas capacidades de comunicación, pero siempre específicas y generalmente unívocas. Existen miles de lenguas humanas en nuestro planeta (5000 hasta el siglo pasado- hoy como 3500), a menudo compartiendo la misma geografía y algunas a no más de unos pocos kilómetros de distancia entre ellas. Esta diversidad y constante plasticidad de los idiomas humanos constituye nuestra verdadera posibilidad de comunicación.

Debemos enfatizar que la diferencia es precisamente la que nos permite comunicación, y no la identidad. Merleau-Ponty resumió así esta aparente paradoja: El algoritmo, el proyecto de un lenguaje universal, constituye una revolución en contra del lenguaje natural. ${ }^{5}$ En sólo dos siglos, el mundo ha perdido cerca de 2000 idiomas y muchos más se encuentran en vías de desaparecer. Esto representa una conmoción en nuestro mundo cultural de una magnitud rara vez sondeado.

El lenguaje, debemos recordar, es co-extensivo con el ser, el lenguaje es cultura, nuestra humanidad está inextricablemente ligada con nuestro ser lingüístico, la imaginación y la arquitectura no pueden operar fuera de este ámbito. Cada articulación lingüística distinta tiene la capacidad de revelar en diversos términos la riqueza del entorno y nuestro propósito como seres humanos en vista de nuestras preguntas más fundamentales, y toda articulación lingüística tiene la capacidad de ser traducida. En efecto, después de recordarnos la importancia de la diversidad lingüística, George Steiner

5 Merleau-Ponty, ibid., p.5. 
ofrece una reflexión profunda sobre las posibilidades de la traducción. ${ }^{6}$

La traducción no sólo es posible, sino que es de hecho central para la comunicación humana. Incluso dentro del mismo idioma que compartimos en el habla cotidiana, traducimos las palabras de los demás en nuestros propios términos, lo que nos permite comprender. Sin embargo, y esto es lo importante, sólo la poesía (la metáfora) traduce emociones y conceptos universales, verdaderamente transculturales, aun cuando para traducir la poesía es menester re-escribirla. Los idiomas humanos son, por definición multi-vocales, originalmente metafóricos. En contraste, el lenguaje algorítmico de la tecnología y la tecno-política es unívoco, aun cuando podamos argüir diferencias regionales superficiales.

Todo esto no significa que debemos evitar las herramientas tecnológicas en la generación de la forma arquitectónica. Por el contrario, debemos utilizarlas plenamente y entender sus posibilidades: la naturaleza de la imagen tecnológica tal y como la describe $\mathrm{Vi}$ lem Flusser, pero con un verdadero sentido crítico, comprendiendo que al ser generadas por mecanismos (químicos o digitales) establecen una distancia con el mundo de la percepción al que frecuentemente pretenden reducir, que en las disciplinas del diseño es menester reconciliar con nuestras intenciones a través del lenguaje cotidiano. $^{7}$

En nuestra disciplina que nos llama a ordenar el entorno humano, a manifestar los valores de lo bello y lo justo, el lenguaje debe

6 Steiner, op. cit.

7 Vilem Flusser, Towards a Philosophy of Photography (London: Reaktion, 2007). mantener su prioridad. Esto significa que el arquitecto debe ser capaz de articular su posición política y filosófica en relación al proyecto, particularmente en las situaciones ordinarias en las cuales las herramientas dictan de manera implícita sus implementaciones de orden instrumental, ya sean formales o funcionales y tienden a ignoran valores culturales. Es nuestra responsabilidad imaginar cómo nuestro proyecto es una promesa para el bien común y los valores encarnados por las instituciones son nuestra responsabilidad ¿Es justo, por ejemplo, diseñar una prisión cuando quizás los carceleros son más nocivos para la sociedad que los supuestos criminales? Dentro de un marco tecnológico estas preguntas parecerían ilegítimas: la única posibilidad supuestamente legítima para la arquitectura sería aceptar la comisión de algún gobierno criminal o alguna corporación y concebirse exclusivamente como un medio de construcción eficaz. Antes de concluir con una mayor especificación del carácter de este lenguaje necesario para una práctica arquitectónica capaz de conjugar lo bello y lo justo, permítaseme ofrecer otras precisiones importantes para evitar malentendidos.

Es importante recordar que la realidad manifiesta de la arquitectura a lo largo de la historia de la civilización es muy compleja. La arquitectura no es fácil de comprender como si fuese un producto de la naturaleza, capaz de exhibir una esencia más o menos constante a lo largo de los siglos. En general la arquitectura se ha manifestado de diversas maneras en diversos momentos históricos, aun cuando es posible argumentar que la disciplina, en sus mejores ejemplos, da sentido a la condición humana, la cual nos pide enfrentarnos siempre a las mismas cuestiones fundamentales para dar razón de 
nuestra mortalidad y a la posibilidad de transcendencia cultural que nos abre el lenguaje.

Las soluciones, sin embargo, son siempre diversas y han cambiado en muchas culturas y a través de la historia. Hoy, por ejemplo, se tiende a asociar la arquitectura con las Bellas Artes, pero en verdad esta categorización data únicamente del siglo XVIII, y no es muy constructiva a menos que se redefina el concepto mismo de arte más allá de una estética formalista. En efecto, y esto es lo que me importa enfatizar: la tradición más profunda de la arquitectura en nuestra civilización humana no comprende simplemente una colección cronológica de edificios cuyo significado fuese deleitarnos por medio de alguna supuesta contemplación estética.

Esta concepción moderna fue solo aceptada a partir del siglo XIX, conjuntamente con los postulados del funcionalismo: la idea de que el arquitecto debía desentenderse de la intencionalidad expresiva, y desacoplando la arquitectura del lenguaje, debía resolver simplemente el problema de la distribución en planta del edificio para que el resultado revelase automáticamente su carácter como un signo. ${ }^{8}$

Este es el primer momento en que la teoría se resuelve en un puro instrumento, en una receta aplicable, y la historia que se construye para acompañarla se presenta ya sea como una colección de tipos edilicios funcionales, cuyos sistemas ornamentales son contingentes y simple cuestión de moda, ${ }^{9}$ o como una secuencia progresiva de diseños estructurales cada vez más racio-

8 Jean-Nicolas-Louis Durand, Précis des leçons d'architecture (Paris, 1819).

9 Durand, Recueil et parallèle des édifices de tout genre, anciens et modernes (Paris, 1800) nales y eficientes, ${ }^{10}$ ambas versiones orientadas hacia el futuro que es la utopía tecnológica.

$\mathrm{Si}$ algo podemos afirmar en general es que la arquitectura en sus diversas encarnaciones históricas ha sido un hacer poético capaz de revelar conceptos y emociones universales asociada a los origines mismos de nuestras sociedades, pero siempre a través de manifestaciones específicas emergentes de una cultura particular. A lo largo de varios milenios la arquitectura ha sido capaz de ofrecer a la humanidad un sentido de orientación existencial: mucho más que algún mero placer o la solución a alguna simple necesidad de orden práctico (como el abrigo de los elementos).

Permítaseme, en vista del camino recorrido, repetir lo obvio: nuestro mundo tecnológico duda frecuentemente de la importancia de la arquitectura. Se pretende que lo único que importa en el mundo construido es su funcionalidad, su sentido práctico y más recientemente, confrontando un mundo cuyos sistemas ecológicos están en crisis, su sustentabilidad entendido esto, en la mayoría de los casos, como una simple mayor eficiencia. Estas concepciones son muy limitadas, y no llevan, como he sugerido, sino al empobrecimiento del entorno con consecuencias nefastas para nuestra sensibilidad colectiva.

Nuestros sueños, donde aparece frecuentemente en forma patente lo más significativo en nuestra experiencia personal, requieren de lugares cargados emotivamente. Debemos aprender a valorizar tales revelaciones, como lo han hecho maravillosamente los artistas, cineastas, novelistas y poetas de múltiples

10 Jean Rondelet, Traité Théorique et Pratique dl'Art de Bâtir 3 vols. (Paris, 1830) y Auguste Choisy, L'art de bâtir chez les romains (Paris, 1873). 
culturas. Los edificios en nuestro entorno dan lugar, literalmente, a nuestro pensamiento y a nuestra imaginación. Incluso el llamado espacio digital que aparece en nuestras pantallas no nos resultaría inteligible si no fuésemos primeramente conciencias encarnadas, mortales y autonómicas, apriori enraizadas en el mundo a través de la direccionalidad e intencionalidad motora del cuerpo negociando su peso con la gravedad del planeta. La nueva ciencia cognitiva y la neuro-fenomenología demuestran cómo incluso la misma percepción visual no es reducible a la imagen (si entendemos por esto una analogía con la fotografía). Tampoco la imaginación (las imágenes mentales) tiene el carácter de fotografía, contrariamente a los supuestos más tradicionales sobre la percepción que pretendían explicar nuestra visión de alta definición como dada simplemente en la retina. La imagen retinal es en realidad muy defectuosa. La percepción nunca es mera pasividad: es acción en el espacio vivido y todo significado depende de esta condición primera.

Es por eso que Merleau-Ponty puede afirmar que la profundidad dada en nuestra percepción frontal es primaria y no simplemente una de tres dimensiones geométricas análogas. ${ }^{11}$ Por tanto, podemos concluir que el espacio arquitectónico es la profundidad significativa, reconocido a través de la historia en los artefactos producidos por arquitectos $y$ artistas diversos, como una pintura china, una miniatura persa o una pintura renacentista; un templo griego o una pirámide tolteca, tan heterogéneos como nuestras culturas y en los que, sin embargo, nos es dado reconocer el sentido de lo humano.

11 Merleau-Ponty, The Primacy of Perception (Evanston IL: Northwestern University Press, 1964).
La arquitectura cumple su misión cuando la experiencia espacial que enmarca resuena con el enigma de nuestra realidad cultural que nos da sentido, cuando se revela como el espacio del deseo que nos permite encontrarnos en casa, al tiempo que permanecemos incompletos y abiertos a nuestra muerte personal. Como lo ha dicho claramente Flusser, en nuestro mundo multicultural podemos argüir que no necesitamos ya más de la casa en el sentido alemán de Heimat que se refiere a sus raíces en un nacionalismo étnico, pero siempre necesitaremos de un hogar, de un lugar para habitar (Wohnung) y que es invariablemente espacio público para nuestra conciencia corporal: mucho más que un simple domicilio personal o nuestras coordenadas electrónicas. ${ }^{12}$

La arquitectura revela su preeminencia cultural al hacer visible un orden en forma de imagen poética en el sentido de Octavio Paz, lo que implica la reconciliación de los opuestos y el reconocimiento y manifestación de nuestros límites, tanto personales como culturales, tanto físicos como mentales. ${ }^{13} \mathrm{Paz}$ ha demostrado asimismo cómo la metáfora o imagen poética dondequiera que se manifieste es el lugar más apropiado para nuestra necesaria percepción de lo sagrado en un mundo totalmente libre de dogmatismos religiosos.

Es así que los productos de una verdadera arquitectura son necesariamente distintos de las construcciones producidas por una mentalidad tecnocrática, más o menos sustentables pero que al final de cuentas, como la pretendida economía global que las engendra, nunca reco-

12 Flusser, Writings (Minneapolis MN: University of Minnesota Press, 2007).

13 Octavio Paz, El Arco y la Lira (México: FCE, 1967). 
nocen límites y se proyectan en función de un crecimiento imperturbable presuponiendo el infinito como si éste existiera en nuestra realidad radical, que es la vida humana. A diferencia de la arquitectura que nos hace patente el espacio incompleto del deseo que tenemos que negociar con prudencia y sin aferramiento, la construcción tecnológica promete la felicidad y el placer de alguna comodidad absoluta, la supuesta culminación del deseo a través del consumo.

A un nivel más personal, es imprescindible entender que para cultivar nuestra vitalidad el deseo no debe objetivarse, que nuestras obsesiones son peligrosas y nos roban nuestra capacidad de entrar en contacto con el propósito inmanente de la vida misma, nuestra única posibilidad de placidez en un mundo secularizado que no puede depender del más allá para revelarnos su sentido último.

Así, podemos argumentar que, en primer lugar, la arquitectura no comunica un significado particular, sino más bien da la posibilidad de reconocernos completos en nuestra apertura existencial, en armonía con un entorno emocional e intelectivo, a fin de habitar poéticamente sobre la tierra y actualizar nuestras capacidades humanas a través de la acción. Y como he sugerido, esta condición no se ha dado a través de la historia sólo en edificios. En la tradición europea, por ejemplo, los productos de la arquitectura incluyen los daidala de la antigüedad clásica, artefactos de muy diverso orden desde armas defensivas como el caballo de Troya o el escudo de Aquiles, hasta templos arcaicos, formados por partes bien articuladas que producen maravillosos efectos luminosos y taumatúrgicos; los relojes solares capaces de proporcionar orientación a la ciudad con respecto a las inmutables direcciones cardinales y las máquinas miméticas del cosmos nombradas por Vitrubio en su tratado, además de los edificios desde luego, como las tres manifestaciones de la disciplina.

Parte de esa amplia tradición son los jardines y la arquitectura efímera de la época barroca, y durante la modernidad, además de las obras importantes de grandes arquitectos como Le Corbusier, Lewerentz, Barragán, Scarpa, Shirai, y Zumthor, entre otros, obras que de acuerdo con las definiciones sugeridas resisten una reducción a la condición de edificios pragmáticos o de simple ejercicio estético, incluyen asimismo los proyectos teóricos, a la vez poéticos y críticos, en una genealogía inaugurada por Piranesi que cuestiona la categorización rígida separando la arquitectura de otras disciplinas artísticas y que incluye a Ledoux, o más recientemente, a John Hejduk, y crucialmente, la obra de otros géneros artísticos mono y multidisciplinarios capaces de revelar una profundidad significativa al habitar.

El sentido comunicado por la arquitectura no es sólo de equivalencia semántica, como un signo, sino que se produce en la experiencia, y como todo poema revela un significado inseparable de la experiencia del poema mismo. Tal sentido nunca es creado por algún autor de la nada, sino que tiene sus raíces invariablemente en la cultura. Es siempre circunstancial y, como experiencia vivida, no es posible objetivarlo, se da como espacio temporalizado en un presente espeso, como la percepción de una melodía que incluye también las notas pasadas y las por venir. Análogo a un evento erótico, desborda cualquier paráfrasis reductiva, abruma al espectador-participante y tiene la capacidad de cambiarle la vida al afectar su sensibilidad más íntima (ese sentir vital y emotivo que nos hace 
conscientes en primera instancia, anterior al pensamiento reflexivo).

En particular, la arquitectura enmarca la vida biológica con el objeto de revelarla al individuo como acción significativa, a través de rituales que tradicionalmente daban orden a la vida en función de lo sagrado. Hoy en día, esta vocación se manifiesta en la habilidad del arquitecto para proponer una vida más rica, cuestionando los falsos valores y las instituciones caducas.

Con el fin de propiciar estos eventos y enmarcarlos de manera adecuada, el arquitecto debe necesariamente involucrar el lenguaje; insisto aquí que no me refiero al supuesto lenguaje arquitectónico como una analogía de alguna sintaxis formal. La invención formal es insuficiente y sus abusos han resultado frecuentemente en la condenación de la imaginación egotista del arquitecto capaz de crear edificios solipsistas o representaciones de la opresión política y explotación corporativa. Y sin embargo, como he sugerido, hoy es también claro que ninguna metodología instrumental para la generación de formas arquitectónicas, operando en un vacío histórico y cultural, puede garantizar un respeto por el prójimo y un entorno rico en significados.

En realidad, como lo han demostrado Paul Ricoeur y Richard Kearney, la imaginación tiene sus raíces, no en alguna inexistente imagen mental, sino en la metáfora, en el lenguaje cotidiano y su original capacidad poética de expresión. Y la imaginación encarnada es indispensable no solo como vehículo de creatividad sino para nuestro sentido empático y ético. ${ }^{14}$ Sólo mediante la imaginación nos es posible

14 Richard Kearney, The Wake of Imagination (Minneapolis MN: University of Minnesota Press, 1988). comprender y sentir como el Otro y desarrollar así un verdadero sentido de compasión.

Debemos aprender a aceptar la muy real e ineludible relación entre nuestras palabras y nuestros actos. Aun cuando esta relación es opaca, pues es fácil comprender cómo la palabra humana (que no es como el verbo divino) no puede producir instrumentalmente un efecto como acción técnica, al igual que una maquina robótica implementando un programa matemático esta relación existe a través de nuestra conciencia encarnada y puede cultivarse.

Enmarcado así por el lenguaje intencional del arquitecto, con una conciencia de valores culturales emergentes de la historia, el proyecto arquitectónico puede valorarse como proceso y no como un medio neutral para alcanzar algún fin preconcebido (como en los modelos de planificación clásica). La intención es identificar, a través del hacer, no solo ciertas formas elocuentes apropiadas a alguna tarea específica, sino el proyecto como vehículo para el bien común.

La principal preocupación de cualquier teoría generativa de la arquitectura es, por lo tanto, desarrollar un lenguaje adecuado que sea capaz de modular el proyecto en vista de los imperativos poéticos y éticos específicos que se dan en relación a cada tarea; un lenguaje como razón histórica que al reflejar valores culturales permita una orientación apropiada de la generación formal y determine su carácter expresivo, tanto emotivo como intelectual. Y un lenguaje empleado asimismo para la elaboración de programas narrativos, para proyectar a través de la palabra compartida un futuro mejor. La práctica que se desprende de una teoría tal nunca puede ser una aplicación instrumental, sino que más bien aparece como un verbo, 
como un proceso que nunca es neutral y debe ser valorizado.

$\mathrm{Si}$, como he sugerido, la riqueza de nuestra humanidad depende de la diversidad de nuestras culturas representadas por nuestros varios miles de lenguas, si la posibilidad de comunicación para el ser humano depende precisamente de esta plasticidad del lenguaje, que nunca funciona con la transparencia y univocidad de alguna lengua pre-Adámica o algorítmica, resulta inconcebible, por tanto, que en nuestro mundo multicultural la tendencia sea obliterar las diferencias. Es una falacia pensar que si todo el universo llegase a hablar un idioma único y totalmente transparente habría menos desigualdad y más justicia, y no habría más malentendidos. Las diferencias entre nuestras culturas son reales, complejas y deben ser celebradas. Es solo a través de su especificidad cultural que la arquitectura ha logrado hablar universalmente, como un poema o una obra de arte que habla fuera del tiempo precisamente por pertenecer íntimamente a su momento y a su lugar.

Es por eso que es imprescindible preservar, en el contexto de la aldea global, la especificidad cultural de las prácticas arquitectónicas. Aun cuando es indudable que la tecnología ha tenido ya un efecto de homogeneización en todo el planeta, la praxis arquitectónica involucra mucho más que medios técnicos: se trata de valores, articulados a través de las historias que dan razón de los actos y hechos en una cultura particular. Esta sabiduría práctica es del orden de la transmisión oral y emotiva, dada a través del idioma mismo, de los gestos que acompañan la elocución a través del cuerpo, primer momento de expresividad y de su mentalidad implícita, emergente también en todos los artefactos que constituyen una cultura: su literatura, su arte plástico y artesanía, su cinematografía y su cocina.

Este es el verdadero contexto físico del proyecto arquitectónico, no alguna representación pictórica de edificios del pasado o alguna imagen digital que muestre las características formales de los edificios contiguos al terreno. Los valores, emergentes en el entorno vital, son preservados por las instituciones y se dan incorporados en nuestras construcciones físicas para ser eventualmente articulados, celebrados o criticados por medio de la palabra.

Quisiera terminar con otra anécdota histórica. A principios del siglo XIX un arquitecto y teórico francés prácticamente desconocido, Charles-François Viel -de quien trato en un libro reciente- propuso una revisión radical de las presuposiciones educativas que en su momento polemizaban sobre la enseñanza de la arquitectura. ${ }^{15} \mathrm{El}$ debate, que nos es hoy muy familiar, era si la arquitectura debería enseñarse entre las artes (en la Escuela de Bellas Artes, con los pintores y escultores) o entre las ciencias, en la Escuela Politécnica de París, con la ingeniería.

Con una sagacidad inusitada para su momento, Viel declaró que ambas opciones estaban equivocadas. En su opinión, la arquitectura debería enseñarse en la facultad de $\mathrm{Hu}-$ manidades, pues su fundamento es la historia y el lenguaje: la arquitectura era fundamentalmente, en su opinión, una posición política y para encontrar una arquitectura apropiada al presente, tanto desde el punto de vista de la forma como del programa, la interpretación de precedentes y el diálogo eran imprescindibles.

15 Alberto Pérez-Gómez, Lo bello y lo justo en la arquitectura: convergencias hacia una práctica cimentada en el amor (Xalapa: Universidad Veracruzana, 2014), p.325-352. 
Hoy, en nuestro tercer milenio, seguimos debatiendo sin considerar la posibilidad de esta tercera alternativa. La arquitectura terminó polarizándose entre aquella de interés social (como la ingeniería) y la otra supuestamente guiada por valores estéticos. Y la discusión continúa.

He sugerido aquí que ambas posiciones son fútiles, que optar simplemente por un modelo mixto - mitad arte y mitad ingenieríatampoco resuelve nada. Debemos revisar radicalmente nuestras suposiciones. Para concebir la posibilidad de una arquitectura que sin ignorar su ubicación en la aldea global nos enriquezca capitalizando precisamente nuestras diferencias culturales, se requiere retomar la posición hermenéutica sugerida por Viel.

El auténtico diálogo con el pasado (con nuestras tradiciones y sus artefactos emotivos) y con el otro ser humano en el presente, el futuro habitante de nuestra arquitectura, es fundamental. Por parte del arquitecto este debe ser un diálogo cortés, que aun cuando crítico se desarrolle en el profundo respeto y sin cinismo, partiendo sobre la presuposición de que todos los productos de las tradiciones culturales responden a preguntas importantes, potencialmente útiles para nuestros proyectos actuales. En otras palabras: el arquitecto no debe simplemente servir los intereses del cliente, su obra tiene implicaciones profundas para la cultura y ellas son su responsabilidad. El cambio de mentalidad que sugiero no es fácil.

Más allá de la estupidez flagrante de una arquitectura de marca que pueda supuestamente ignorar la realidad del contexto físico y cultural para aterrizar en el terreno de construcción a través del Internet, es ingenuo pensar que la arquitectura puede ser verdaderamente regional por la simple adopción de algunos mecanismos formales relacionados con tradiciones locales.

Como he reiterado, la comunicación de los valores culturales es más profunda, y se manifiesta en los idiomas, los hábitos y las narrativas. La interpretación de esta herencia nos permite hablar con autoridad y manifestar una posición para nuestra arquitectura aquí y ahora, como el arte de la retórica tradicional. Esta táctica afectará no solo las decisiones formales, sino también y en forma fundamental el programa: la promesa que hace el arquitecto para una vida más rica y armoniosa, sana y resonante con nuestras necesidades psicosomáticas. Así entendido, el programa se convierte en una historia narrativa motivada por el bien común que el arquitecto debe tejer incluyendo desde luego las aspiraciones presentes en los relatos de sus futuros moradores. Se trata de una negociación política, de una intención poética y no simplemente de una lista de piezas o espacios con sus dimensiones respectivas. 